Proceedings of the 50th Hawaii International Conference on System Sciences | 2017

\title{
Continuous feedback as a key component of employee motivation improvement - a railway case study based on the placebo effect
}

\author{
Witold Bartnik \\ REDS SA \\ witold.bartnik@reds.com.pl
}

\author{
Małgorzata Ćwil \\ Kozminski University \\ mcwil@kozminski.edu.pl
}

\begin{abstract}
The objective of this paper is to present and analyse results from a placebo-based case study concerning the importance of feedback in achieving continuous improvement of train driver motivation. The specifics of the train driver job, which affect motivation are presented, along with motivation theory. The case study, conducted using the placebo effect for three months in a medium-sized Eastern-European railway operator is then presented along with the results. These results show that informing the employees that their efficiency was being monitored and that the best drivers would be rewarded improved efficiency. However, the lack of feedback and stimulation of only extrinsic motivation, caused the employees to lose motivation to improve and further consumed energy reduction could not be observed. These results are analysed and used to validate a proposed gamification system aimed at achieving continuous improvement of employee motivation via a set of gamified techniques and continuous feedback targeting the four basic human needs of competence, relatedness, autonomy and purpose.
\end{abstract}

\section{The specifics of a train driver job}

Driving a train is one of the more demanding jobs on the market and entry barriers are, contrary to popular belief, quite high. Potential and current train drivers must prove (repeatedly, usually every 2 years) complete physical readiness for the job - which means that they possess 20/20 eyesight], perfect hearing and do not suffer from any conditions which may render their driving dangerous [33]. There are also numerous rules and signs that drivers must remember and follow, as well as technical information concerning the operation, service and simple repair of railway rolling stock. All these requirements stem from the fact that trains are usually very heavy (50 to several thousand times more massive than cars) and often drive at high speeds, which makes for long braking distances and large collision masses and speeds and explains why their consequences are usually very serious. This is also the reason for a very complicated and formalised railway traffic control - the rules of which every driver must know through and through.

The driving process in itself is also more complicated than it seems [27]. Firstly, shifts are often long (up to 12-14 hours) and provide little or no stimuli other than the repetitive process of accelerating and braking the train, opening the door (in case of passenger trains) and waiting for signals. Furthermore, due to potentially catastrophic consequences of a runaway train, almost all rolling stock is equipped with a dead man's switch - usually in the form of an alerter - a device which buzzes every few seconds. If the train driver does not push the button in the short time limit (5-10 seconds) the train automatically begins full emergency braking, which may result in delays and harm to passengers. This means that the driver must repeatedly, a few hundred times per shift, press a button in order to confirm he is still in control of the vehicle. These specifics cause the job of a train driver to be very dependent on habits.

Another specific problem of this line of work is the lack of feedback on its quality. Drivers are usually paid by the hour of provided work and the only feedback they get is when they fail to follow a rule (stop at a signal, stop at the right place at the station etc.) or when they arrive late at their destination. Delays are a very imprecise way of judging driver performance because they are often caused by events that are outside the control of the driver - infrastructure, signalling or vehicle failures, weather or large numbers of people entering and exiting the train at a station.

In general, the work of train drivers carries large demands due to safety, norms and long hours of work but there is little reward for those who do their job extraordinarily well. The aforementioned problems with lack of feedback concerning driver performance have led to the research problem discussed in this paper- can drivers be motivated to drive more efficiently by the 
simple fact of informing them that their performance is being monitored? It is also important to determine whether any potential increase in quality of work can be sustained despite using only placebo effect.

\section{Motivation theory}

The key component in achieving high quality of performed work is employee motivation. A motivated person is someone who feels an impetus or inspiration to act in a certain manner or towards a goal [39]. People differ not only in the level of their motivation but also in its type. Numerous theories have been put forth concerning how motivation is formed, what drives it and how to influence it. The authors have decided to base their research on these theories that stress the qualitative aspect of motivation. Two distinct ways of differentiating motivation have been chosen: one relates to the rewarding or punishing aspect of motivation (positive vs negative) and the other to the localization of the motivational drivers for the employee - whether he is driven by internal or external factors (intrinsic vs extrinsic).

\subsection{Negative vs positive motivation}

The first major division is based on the opposition of positive and negative motivation [35]. Positive motivation means that the employee gets rewarded for performing well in his job, for example achieving a certain level of turnover, producing a fixed amount of equipment or delivering a certain number of packages. This type of motivation is driven by reward and therefore voluntary - the employee is free to participate in the program, but not reaching the required levels of performance does not carry any penalty. Many companies, however, use performance-based rewards as the main component of employee compensation and set the basic pay so low that workers have no choice but to pursue rewards [12]. Positive motivation can of course also be based on other means than monetary - it can take the form of praise, working hour reduction, nonfinancial incentives like gym membership or health insurance, courses, study programs etc.

Negative motivation on the other hand is based on forcing employees to work as hard as possible through fear of the consequences of failing to achieve the pre-set objectives or performing in accordance with rules. These consequences can range from criticism and financial penalties to downright demotion or termination of employment. This kind of motivation used to be the main motivator for most companies, but it is generally recognised nowadays as being somewhat anachronistic. It is worth noting though that negative motivation can be found in most job positions related to human safety, like pilots, train and bus drivers, level crossing attendants etc. It usually takes the form of certain penalties for not conforming to strict norms in order to ensure that these norms are not broken.

This differentiation between positive and negative motivation has been repeatedly mentioned in numerous sources. As early as the second half of the 19th century scholars like William James [23] and Freud [16] have claimed that pain and pleasure can act as very strong reinforcers or inhibitors of behaviour and this idea has become one of the mainstays of psychology and is considered fundamental in many motivational analyses [see $2 ; 3 ; 14 ; 20$ ]. Elliot [13] divides motivation into two types: approach motivation based on modifying behaviour and actions towards positive stimuli and avoidance motivation aiming to modify behaviour away from negative stimuli. This division mirrors the one described in this paragraph and confirms its mainstream character in modern psychology.

\subsection{Intrinsic vs extrinsic motivation}

Another common distinction of motivation is between intrinsic and extrinsic. Motivation is called intrinsic when people want to do something - this description is based on the fact that for those people motivation lies inside that activity. Extrinsic motivation, meanwhile, is present when people feel the need to do something - for these people motivation lies outside of the activity [46]. Extrinsically motivated people engage in behaviours in order to obtain rewards and praise or to avoid criticism and punishment [45].

Detailed analyses concerning intrinsic-extrinsic division have been performed by Ryan and Deci and described in the form of Self-determination Theory (SDT) [40]. SDT has been very successful and has yielded over 400 empirical publications since the early 1980s. It has been shown to work in various areas, for instance: education [38], sport, health care [47; 30], environmental issues [34] and employee motivation [1; 32]. It has also been shown that regardless of the culture, satisfying these needs corresponds to increased psychological well-being [6]. SDT does not view intrinsic and extrinsic motivation as two opposing states, but rather claims that they form a continuum. This continuum begins with amotivation, a state of no motivation, goes through extrinsic motivation where external stimuli are main behaviour drivers and ends with intrinsic motivation, where behaviours are driven by an inner need. According to SDT, in order to increase employee motivation, it is important to move toward motivation internalisation [7]. Motivation internalisation is a process in which an external regulation becomes internal. SDT claims that this 
internalisation can be achieved by appealing to three basic needs - competence, relatedness and autonomy.

Competence is the process of becoming more skilled in a given activity and eventually mastering it in a way that would label one an expert. Relatedness is usually described as the feeling of belonging to a well-defined community and enjoying interactions fostered by that community. This need is key to retaining employee engagement and loyalty. Autonomy is understood as a sort of freedom, agency, the feeling of not being under someone's control. Daniel Pink [35] adds a fourth need - purpose, defined as a feeling of greater meaning or a desire to be altruistic.

It is only by influencing and responding to all of the basic needs that a proper intrinsic motivation can be achieved. Stimulating only one of these needs usually fails to lead to motivation internalisation [10]. When people become oriented towards intrinsic values, they experience greater well-being than people who remain oriented towards extrinsic values [24] and it is an important fact to remember when designing motivation systems.

\subsection{Feedback}

An important part of successful employee motivation is feedback. Feedback is anything that gives its recipient some understanding of his/her progress and achievement [18]. Without feedback employees do not know whether the quality of work they provide is acceptable, whether the work itself is meaningful and how they can improve and become better at what they are doing - which relates directly to the aforementioned competence need. Success feedback will usually raise the recipient's expectations towards the outcome and induce approach motivation whereas failure, i.e. negative feedback will in most cases lead to avoidance motivation [15]. The way feedback is provided is, however, as important as its content.

Firstly, feedback needs to be relevant, that means in context with the activity performed. Secondly, it must be delivered in time. This requirement is critical, because only when the employee is informed about the quality of his/her work in an acceptably short time period after it has been performed can they relate to and understand that feedback. Delaying feedback in a reasonable manner can lead to increased curiosity and arouse interest in its recipients but this method needs to be used carefully and sparingly - otherwise it loses its effect. And lastly, feedback needs to be meaningful rewarding or punishing every little action performed by the employee dilutes the real message of the motivator and significantly decreases the chances that the worker will understand and internalise the feedback's content, although this last statement is not derived from scientific research but rather from the practical work of Marczewski [28].

\subsection{Past vs current approach towards motivation}

In the past, negative motivation used to be considered the best type of motivation. A large metaanalysis from the 90s [25] reviewed research on feedback interventions (FI) defined as actions taken by external agents to provide information regarding some aspects of one's task performance. The results show that feedback interventions have a variable influence on employee performance, i.e. in some conditions they can have a great positive effect, in others they have no apparent effect whatsoever whereas in some conditions they can even debilitate performance. In accordance with Thorndike's law of effect positive FIs were equated with reinforcement (i.e. reward) and negative ones with punishment. Thorndike posited in the beginning of the $20^{\text {th }}$ century [42], when the idea of behavioural conditioning had not even been born, that actions met with positive reinforcement have a greater chance of being repeated whereas responses that produce a discomforting effect become less likely to occur. In light of this both positive and negative FI should improve performance because the former reinforces correct behaviour (the sole objective of FI for railway operators and regulators) whereas the latter punishes the incorrect behaviour. FI change the focus of attention and therefore affect the behaviour of their recipients. The most current research at the time of the meta-analysis appeared to support the thesis that negative FI are likely to exert more influence than their positive counterparts but usually in a situation where their recipients had an opportunity to attain their self-goals. FI were also shown to work better when employees had a clear goal to aspire to, they were highly committed to it and their belief in final success was strong.

The approach to employee motivation has undergone strong changes since the late 20th century. Currently a much stronger emphasis is put both on intrinsic and positive motivation $[7 ; 28 ; 40]$. How then can train drivers be motivated in order to encourage performance that operators and regulators seek?

\subsection{Changing the focus of driver motivation}

The approach to motivating train drivers has always been focused on the negative motivators. The character of the job forced companies and regulators to ensure that train drivers stay focused and follow the rules. This was also justified by a long history of railway accidents caused by drivers that did not adhere to safety rules, especially the ones falling under the category of signal 
passed at danger (SPAD) $[5 ; 26 ; 29]$. The reasoning behind this was straightforward: simple errors in judgement or lack of concentration lead to large loss of life and material. It was therefore highly desired that drivers be motivated to stay focused. This important public need was further aggravated by the lack of modern capabilities - nowadays sophisticated computer systems can ensure (albeit not 100\%) that trains adhere to the speed limit, stop signals and at the same time make it impossible for train dispatchers to put two trains on a collision course.

The first step to achieve the desired motivation increase is to change the emphasis of motivators used. It is difficult to imagine that negative motivators can be discarded completely in the railway context, it is, however, possible to use rewards and other types of positive motivation to change the general outlook of how employees are influenced. At the moment efficient train driving is theoretically required of drivers but since it is in no way controlled and does not affect the driver's job it can be assumed that the current state of driver motivation towards saving energy can be described as amotivation. Figure 1 presents two motivation continua used in this article. Setting up financial rewards or penalties would put the motivation state in the extrinsic half of this figure. The goal of the presented gamification framework is to move the driver motivation towards the intrinsic and positive quarter of the figure.

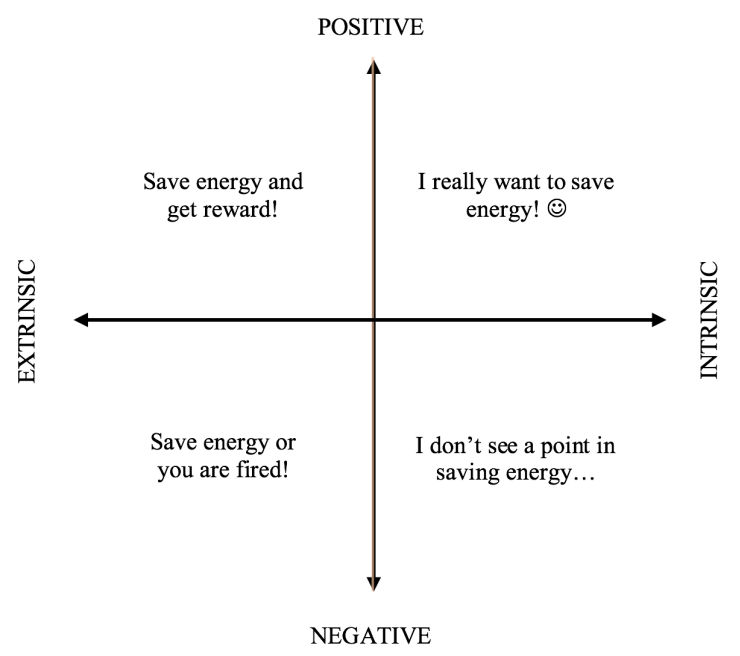

Figure 1. Motivation continua

\section{Train driver motivation in the context of Eco Driving}

In mid-2015 the company employing one of the authors, which offers energy efficiency improvement services to railway operators, encountered a problem how to stimulate the motivation of train drivers working for one of its clients, a medium-sized railway operator in Eastern Europe. In order to achieve this goal a gamification-based approach was chosen and therefore a cooperation was started between the company and the university of the second author. The university-based author supported by her department provides a gamification framework based on previous university experiences in gamification implementation in return for access to data, which may be published anonymously. At the point in time when this research was conducted, however, the software that is necessary for gamification implementation was still in development, so the company decided to perform a feasibility test to determine whether train driver motivation could be influenced and whether this influence affects energy consumption.

\subsection{Eco Driving}

Trains are considered an ecological means of transport, mainly due to high efficiency in moving large numbers of people and substantial quantities of goods over railway transport - it decreases labour cost (one train driver can carry as many people as dozens of buses) and requires less energy because of the low friction coefficient between steel wheels and rails, which is about 10 times lower than the corresponding coefficient for cars - rubber on asphalt. Despite those advantages, reducing the energy consumption is still a major objective for most railway companies, especially since energy costs constitute a large part of expenditures for most of them [36; 37]. One way of achieving this goal is to implement eco-driving - i.e. energy efficient driving. This idea has already been developed in the road transport industry and many modern cars possess some eco-driving features that inform the driver how efficiently he is driving [31].

The current situation in the company researched, and the whole national market on which it is operating is that no information regarding energy consumption is relayed to train drivers. Since development of tools allowing for accurate measurement and assignment of energy consumption to drivers is difficult only the company that our research is based on is in possession of such knowledge. The effects of lack of meaningful feedback are foreseeable - the distribution of average unit energy consumption is characterised by a quite large variance. It has been already established by UIC [43] that the best drivers can save as much as $10 \%$ energy while performing their job on the same routes and driving the same type of train. The key question is: how to use that information to achieve the desired energy use reduction? 


\begin{tabular}{|l|c|c|c|c|c|c|c|c|}
\hline & Train 1 (E) & Train 2 (W) & Train 3 (E) & Train 4 (W) & Train 5 (E) & Train 6 (W) & Train 7 (W) & Train 8 (E) \\
\hline July $[\mathrm{kWh}]$ & 243.1 & 193.15 & 196.03 & 228.19 & 238.19 & 172.93 & 209.08 & 254.35 \\
\hline August $[\mathrm{kWh}]$ & 249.31 & 167.54 & 173.29 & 214.03 & 231.65 & 156.3 & 194.97 & 255.63 \\
\hline Change \% & $2.55 \%$ & $\mathbf{- 1 3 . 2 6 \%}$ & $\mathbf{- 1 1 . 6 0 \%}$ & $\mathbf{- 6 . 2 1 \%}$ & $\mathbf{- 2 . 7 5 \%}$ & $\mathbf{- 9 . 6 2 \%}$ & $\mathbf{- 6 . 7 5 \%}$ & $0.50 \%$ \\
\hline Asymp.Sig. & 0.601 & $\mathbf{0 . 0 0 0}$ & $\mathbf{0 . 0 0 0}$ & $\mathbf{0 . 0 4 3}$ & 0.387 & $\mathbf{0 . 0 0 0}$ & $\mathbf{0 . 0 7 6}$ & 0.578 \\
\hline September $[\mathrm{kWh}]$ & 269.24 & 201.89 & 193.17 & 183.08 & 200.04 & 160.88 & 177.3 & 250.32 \\
\hline Change \% & $7.99 \%$ & $20.50 \%$ & $11.47 \%$ & $\mathbf{- 1 4 . 4 6 \%}$ & $\mathbf{- 1 3 . 6 5 \%}$ & $2.93 \%$ & $\mathbf{- 9 . 0 6 \%}$ & $\mathbf{- 2 . 0 8 \%}$ \\
\hline Asymp.Sig. & $\mathbf{0 . 0 0 4}$ & $\mathbf{0 . 0 0 0}$ & $\mathbf{0 . 0 0 3}$ & $\mathbf{0 . 0 0 0}$ & $\mathbf{0 . 0 0 0}$ & 0.286 & $\mathbf{0 . 0 0 8}$ & 0.272 \\
\hline
\end{tabular}

Table 1. Monthly average energy consumption per scheduled train

\subsection{Placebo test in a railway operator}

In the first part of the test train drivers on a single rail line were informed that their energy consumption would be monitored from now on. Due to the complicated calculations needed to extract energy consumption per driver and the lack of the necessary software at the time of this test, the railway line was chosen for its seclusion and relatively small traffic (4 pairs of trains per weekday). Since the tools necessary to perform that monitoring were unavailable at that time, this test was in reality a placebo test - its goal was to find whether the simple fact of trying to drive more efficiently can lead to energy savings.

The sample consisted of 736 observations (92 days, 8 trains on each day), that is single train rides on the researched line. For 79 (10.7\%) observations there was no data about energy use. This missing data may have been caused by technical problems with electricity meters or GPS trackers onboard the trains or by transmission problems between the train and the data server. It is worth noting that in cases where the energy data for a given train was incomplete (some energy reads missing) the whole observation was excluded from analysis. The resulting sample was well balanced $-49.5 \%$ observations concerned trains going in the western direction and $50.5 \%$ trains going east. All the train drivers in the sample were male.

The largest energy consumption was registered in July $(\mathrm{N}=216, \mathrm{M}=215.94, \mathrm{SD}=37.37)$, which was the first month of the test and served as the basis for comparison with the following months. The train drivers were informed that efficiency monitoring on the chosen line would start on August $1^{\text {st }}$. Consequently, energy consumption in August fell by $4.81 \%(\mathrm{~N}=234, \mathrm{M}=205.55, \mathrm{SD}=41.91)$. It fell again in September $(\mathrm{N}=207, \mathrm{M}=204.19, \mathrm{SD}=42.40)$, although only by $0.66 \%$ compared to August.

In order to compare the mean energy consumption for each month a t-Student parametric test was performed to determine whether there is a statistically significant difference month-to-month. This method can be used due to the large sample. A significant difference in energy use was registered between July and August, $\mathrm{t}(448)=2.78, \mathrm{p}<.01$ with higher energy use in July. There was, however, no significant difference in energy use between August and September, $\mathrm{t}(439)=0.34, \mathrm{p}=0.74$.

Table 1 shows the monthly average energy consumption per ride for each of the eight trains run daily by the operator on the researched line. Between July and August 6 out of 8 trains registered a reduction of energy use, whereas between August and September half of the trains registered increased consumption and the other half - reduced. In order to determine the statistical significance of differences between monthly energy means a Mann-Whitney-U test was performed. It was necessary to use a nonparametric test because the sample sizes were small and their distribution was not normal. The results of these tests are also shown in Table 1, it is worth noting, however, that at significance level of [alfa] $=0.1$ for 5 out of 8 trains the energy consumption reduction between July and August was significant. Between August and September 3 out of 8 trains increased and 3 out of 8 trains reduced average energy consumption significantly.

The most interesting results were achieved by Train 2 as documented by Figure 2, whereas a different outcome of the case study is presented by Figure 3 . 


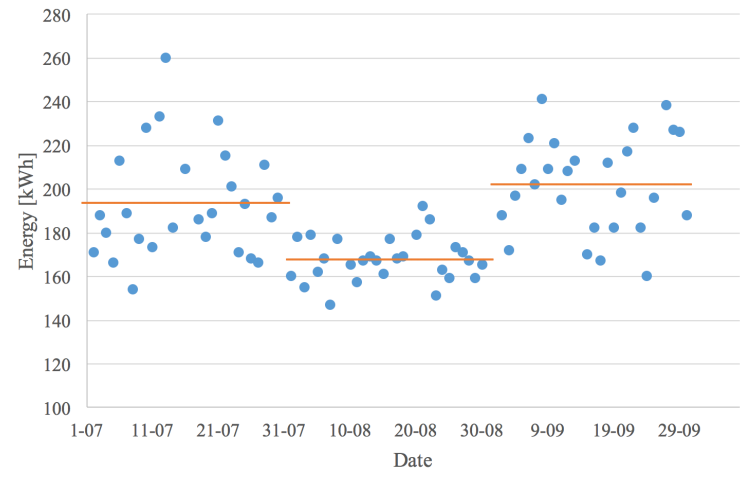

Figure 2. Energy consumption for Train 2 from the $1^{\text {st }}$ of July to the $30^{\text {th }}$ of September (Monthly average consumption in orange)

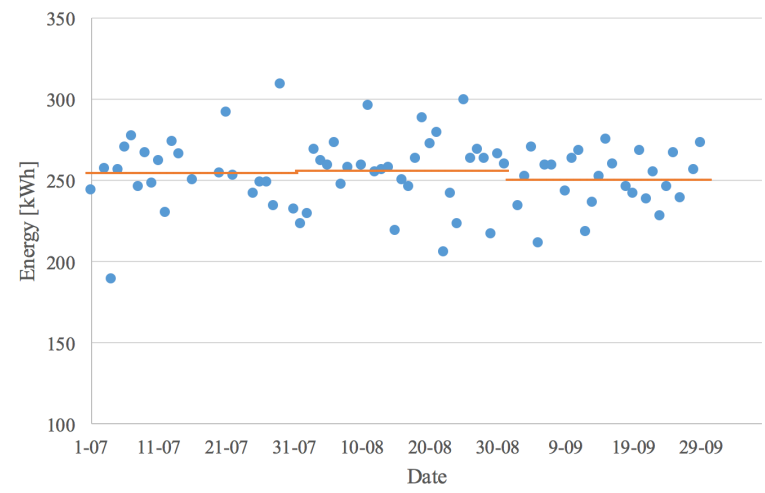

Figure 3. Energy consumption for Train 8 from the $1^{\text {st }}$ of July to the $30^{\text {th }}$ of September (Monthly average consumption in orange)

Although it can by no means be said that this was a general tendency, Figure 2 shows an interesting trend. Energy consumption fell from July to August, when drivers tried to improve their effectiveness following the announcement of the observation period. In September, however, when it turned out that there was no follow-up and, most importantly, no feedback directed at drivers, energy consumption returned to the levels seen 2 months earlier.

Figure 3 shows on the other hand that the effect observed for Trains 2 and 3 was not present in every train researched - in some cases the consumption did not show any statistically relevant change whereas in others it continued to fall in September.

It is worth noting that trains in the eastern direction had a tighter schedule which made it more difficult for drivers to save energy, as shown by Table 2 .

\begin{tabular}{|l|c|c|}
\hline Direction & East & West \\
\hline July [kWh] & 230.98 & 200.34 \\
\hline August [kWh] & 226.31 & 184.44 \\
\hline Change \% & $-2.02 \%$ & $-7.94 \%$ \\
\hline September [kWh] & 227.81 & 181.32 \\
\hline Change \% & $0.66 \%$ & $-1.69 \%$ \\
\hline
\end{tabular}

Table 2. Average monthly energy consumption per direction

West-bound trains were found to consume less energy $(\mathrm{N}=325, \mathrm{M}=188.64, \mathrm{SD}=31.02)$ than the eastbound ones $(\mathrm{N}=332, \mathrm{M}=228.02, \mathrm{SD}=40.02)$. This difference in energy use was statistically significant, $\mathrm{t}(655)=-14.1, \quad \mathrm{p}<0.01$. Statistical analysis also determined that the reduction of energy use between July and August was statistically significant only for trains travelling west (Chi-Square $(2)=21, \mathrm{p}<0.01$; east-bound trains: Chi-Square $(2)=0.83, p=0.66)$. This relation between the scheduled time reserve and possible energy savings is a potential interesting subject of future research in the area of transportation.

These results show that without feedback employee performance improvement is unsustainable. Short-term action leads only to a short-term spike in efficiency followed by return to the mean. Another solution is therefore needed in order to achieve the sought performance improvement. This solution, in our opinion, is to implement a comprehensive gamification system aimed at providing drivers with timely, meaningful and helpful feedback. The rudiments of such a framework are provided next.

\section{Gamification in transport environment}

Gamification is defined as using game-like elements in a non-gaming context. Hamari [17] claims that using game design to internalise motivation is a very popular trend at the moment. The idea of using game elements and design in order to increase intrinsic motivation is based on observing the surprisingly high and passionate engagement people seem to demonstrate whilst taking part in theoretically unimportant or unrealistic recreational routines like board or computer games. This game-related motivational trend is relatively new. The term gamification was first used in 2008 in a blog post by Brett Terrill. According to Huotari [21; 22], gamification refers to a process of enhancing a service with affordances for gameful experience in order to support users' overall value creation. A different definition given by Detering [8] refers to the use of game design elements in non-game contexts. Meanwhile Werbach [44] defines gamification as "the 
process of making activities more game-like" adopting a designer point of view.

Gamification has already been implemented in the transport industry. Most studies and programs in this subject concern individual car drivers. The objectives of these gamified efforts vary but the most popular areas include speed control, navigation and ecodriving [9]. Some focus on safety by rewarding drivers adhering to speed limits and in certain cases measuring forces acting on the vehicle via accelerometers to evaluate the driver's technique. A speed camera lottery was used in one case in Sweden $[4 ; 9]$, where a portion of fines paid by speeding drivers was pooled. The drivers who did not exceed the speed limit were then entered into the lottery which resulted in some of them winning prizes. The speed camera itself displayed a thumbs-up signal to law-abiding drivers and a thumbs-down signal to the speeding ones. This innovative approach resulted in a drop of average speed from 32 to $25 \mathrm{~km} / \mathrm{h}$. Waze on the other hand focuses on navigation and traffic information rewarding drivers contributing to the system $[4 ; 9 ; 48]$. A whole experience-based system was developed wherein drivers progress from Waze Grown-Ups through Warriors and Knights to Royalties.

Due to the ever increasing focus on ecology carmakers have also began to promote techniques enabling lower fuel consumption - i.e. eco driving. Numerous new cars are equipped with software evaluating the way the car is driven and helping the driver to reduce fuel usage by giving advice relevant to the current situation (for example in companies like Scania, Nissan, Volvo and Fiat) $[9 ; 19 ; 41]$. The Fiat Eco:Drive solution [11] is especially interesting due to its usage of a gamified online system where drivers can check their results and compare them to other users. Special ecology-related badges are also awarded to the most energy-efficient drivers. These gamified tools resulted in an average $6 \%$ fuel consumption reduction with some drivers achieving $16 \%$.

Stam [41] describes a system developed by Scania Benelux aiming to reduce fuel consumption by engaging truck drivers in a portal game, where the fleet goals were personalised toward driver goals. The main idea of the project was centered on "infotainment", a mixture of information how to drive effectively and how energy efficiency influences the environment, and entertainment - the gamification portal, where drivers competed with each other. Incentives were also added in the system. The overall effects of the projects were positive - driver motivation was substantially increased, while fuel consumption fell by $10-15 \%$.

\section{How to improve - a gamification framework}

The main premise of the proposed system to improve work performance of train drivers is to create a gamification framework based on motivation theory. This system ought to appeal to employees' inner motivation via a set of gamified techniques. As the results from the aforementioned test in Chapter 3 have shown, collecting data about energy use is not enough by itself. A traditional approach to this problem has been to create incentive systems that would return a part of savings on energy to drivers. This solution is not so efficient, however, because external motivators are not the best way to influence people when longterm engagement is desired. Deci and Ryan [40] have shown that tangible rewards may actually lead to intrinsic motivation decrease. In order to avoid that outcome positive, intrinsic motivation needs to be influenced.

To achieve this intrinsic motivation stimulation a four phase approach is proposed. To ensure that the proposed gamification framework meets the motivational requirements a battery of tests will be run after each of these phases. Results of these tests will influence development of subsequent phases. The objective of this phased development is to retain the ability to change the implementation plan in order to achieve the best possible fit to the desired intrinsic motivation increase.

\section{Phase 1}

The first phase will be focused on providing feedback. Its goal is to create a habit of regularly checking one's results on an online platform, which allows drivers to find out how efficient, taking energy use into consideration, their work in the last few days has been. This knowledge will be provided in the form of a specially designed dashboard containing information about the drivers' last trips: how much energy they have used and how much have they saved. In order to ensure high engagement and participation special badges rewarding new and regular users will be implemented. Examples of these badges include a badge for first log-in into the system and they will in general be awarded to users checking their results often. It is very important to ensure that results published online are verified so that the condition of feedback being meaningful is fulfilled. This phase will appeal to autonomy due to its voluntary character and to competence because information about performance will be obtained. Relatedness meanwhile will be influenced through information that all drivers are in the system (whether they choose to use it or not). 
During phase 1 implementation driver engagement will be measured both quantitatively (energy consumption, logon frequency, average period between logons) and qualitatively (in-depth interviews).

Phase 2

The onus of the second phase will be on comparison. Drivers will receive information how their efficiency compares to the average for the routes on which they are travelling. Engagement will be enhanced by missions aiming at driver competence such as "Save $100 \mathrm{kWh}$ on route X". Additional badges will also be introduced in this phase. Their goal will be to reward driver performance. In this phase an incentive system should also be launched rewarding the best and the most improved drivers, further influencing competence and autonomy. The drivers' purpose need will be stimulated by the knowledge that the energy they are saving is beneficial both to the company and to the environment.

During phase 2 tests will focus on mission participation and the influence of these missions on driver engagement and their performance in terms of energy consumption. Logons will continue to be measured in order to monitor if the system continues to fulfil the preliminary requirements and keeps its users engaged.

Phase 3

The main goal of phase 3 is to sustain driver engagement by appealing to relatedness through group competition and cooperation. Drivers will take part in challenges designed to foster group identity, for example of drivers under one instructor or based at the same depot. Feedback concerning group performance will be shown in the driver dashboard in the portal. This feedback will be continuous, positive because only the best drivers will be distinguished and it will affect intrinsic motivation.

During phase 3 tests will focus on whether appealing to relatedness through group competition and cooperation influences results of these groups compared to results achieved during the first two phases. In-depth interviews with instructors and selected drivers will be used to measure whether driver group engagement has risen after introducing new relatedness-influencing elements.

Phase 4

This last phase will be focused on two main points. The first is using the portal and feedback to create a small driver society able to exchange information, tips and so on. The second is to engage the best drivers. Competence will be stimulated by employing best drivers' knowledge and experience to help other drivers improve, while the social part of the portal will influence relatedness. The main point of feedback in this phase is to make the best employees aware, that their excellence serves not only their personal results but also their co-workers and the company as a whole.

Phase 4 efficiency will be tested by analysing the newly created social module of the system - that is if drivers and instructors engage in cooperation and discussion and whether the system is used to advise and help other users.

Phasing the implementation of the system serves multiple purposes. New types of motivators are introduced in each phase in order to maximise the changes of achieving higher user engagement. Each phase is accompanied by a battery of tests ensuring that the system performs its tasks with regard to energy efficiency. Table 3 sums up how different types of feedback used in the system affect basic human needs as defined by theory.

\begin{tabular}{|l|c|}
\hline Feedback & $\begin{array}{l}\text { Basic } \\
\text { needs }\end{array}$ \\
\hline $\begin{array}{l}\text { Efficiency of last rides } \\
\text { Consumed energy information } \\
\text { Badges for most efficient trips } \\
\text { Badges for trips more efficient } \\
\text { than the average }\end{array}$ & Competence \\
$\begin{array}{l}\text { Levels } \\
\text { Group leaderboards }\end{array}$ & \\
\hline $\begin{array}{l}\text { Group leaderboards } \\
\text { Driver society } \\
\text { Information that all drivers are in } \\
\text { the system }\end{array}$ & Relatedness \\
\hline $\begin{array}{l}\text { Voluntary character of the system } \\
\text { Missions and their voluntary } \\
\text { character } \\
\text { Challenges }\end{array}$ & Autonomy \\
\hline $\begin{array}{l}\text { Quantity of energy used } \\
\text { Potential savings } \\
\begin{array}{l}\text { Positive influence on the } \\
\text { environment }\end{array}\end{array}$ \\
\hline
\end{tabular}

Table 3. Different types of feedback used and human needs influenced by them

The potential effects of the gamification framework will be measured both quantitatively and qualitatively. The amount of consumed energy will be analysed both globally and per driver and route. Factors like driver experience, frequency of training (both real world and simulated) and age will be taken into account. In-depth interviews with selected drivers and instructors will be used to measure motivation, satisfaction (with regard to the system) and the influence of the framework on driver performance. These results will provide the answer if the proposed 
solution has met its goals, how it can be improved and whether it is reproducible in different conditions.

It would be beneficial to identify which gamification mechanics used in the system influence driver behaviour. This, however, is a difficult task because gamification frameworks are usually designed as a whole system. Two factors might prove to be helpful in this aspect. Firstly, the phased character of the implementation can be used to determine which of the mechanics had the greatest effect on the results. Secondly, implementations among different customers may differ slightly and their comparison might serve to evaluate individual mechanics.

\section{Conclusions}

Modern research has shown that multiple tactics used to increase employee performance that used to be considered best do not influence workers very well, especially in terms of long-term motivation and engagement. Among these techniques negative motivation, financial incentives and lack of continuous feedback can be named. The placebo test research performed on a chosen railway line confirmed that lack of feedback causes the performance improvements to fade away in a time as short as a month. Accordingly, a different approach was presented, based on positive motivation, continuous, timely and meaningful feedback stimulating employee autonomy, relatedness, competence and purpose and therefore influencing intrinsic motivation which is the key component of achieving successful employee engagement. This system has been designed in accordance with modern theories concerning employee behaviour and motivation and should be implemented in the upcoming months. Performance of this system will be measured both qualitatively and quantitatively throughout the whole implementation and these tests should provide the answer whether this is a good method of influencing, increasing and internalising train driver motivation. As of August the first version of the system has been launched and test implementation should begin by the end of September.

\section{References}

[1] Baard P.P. (2002). Intrinsic Need Satisfaction in Organizations: A Motivational Basis of Success in ForProfit and Not-For-Profit Settings, [in:] Handbook of SelfDetermination Theory, The University of Rochester Press, NY 2002.

[2] Cacioppo, J., \& Bernston, G. (1994). Relationship between attitudes and evaluative space: A critical review, with emphasis on the separability of positive and negative substrates. Psychological Bulletin, 115, 401-422.
[3] Carver, C., \& Scheier, M. (1998). On the self-regulation of behavior. NY: Cambridge University Press.

[4] Chou, Y. K. (2015). Actionable Gamification: Beyond Points, Badges, and Leaderboards. Octalysis Media.

[5] Cullen, W. D., \& Cullen, L. (2001). The Ladbroke Grove Rail Inquiry, HSE Books.

[6] Deci, E., \& Ryan, R. (2008). Self-determination theory: A macrotheory of human motivation, development, and health. Canadian psychology/Psychologie canadienne, 49(3), 182.

[7] Deci, E., \& Ryan, R. (2014). The importance of universal psychological needs for understanding motivation in the workplace. The Oxford Handbook of Work Engagement, Motivation, and Self-Determination Theory, 13-32.

[8] Detering S., Dixon D., Khaled R., Nacke L. (2011). From game design elements to gamefullness: Defining "gamification", Proceedings of the 15th International Academic MindTrek Conference: Envisioning Future Media Environments (pp. 9-15), New York: ACM, http://doi.org/10.1145/2181037.2181040.

[9] Diewald, S., Möller, A., Roalter, L., Stockinger, T. and Kranz, M., Gameful Design in the Automotive Domain Review, Outlook and Challenges. In Proc. Automotive UI 2013 (2013), 262-265.

[10] Dysvik, A., Kuvaas, B., \& Gagné, M. (2013). An investigation of the unique relations between basic psychological needs and intrinsic motivation. Journal of Applied Social Psychology, 43, 1050-1064.

[11] http://ecodrive.driveuconnect.eu/, [access: 31/08/2016]. [12] Eisenberger, R., Pierce, W. D., \& Cameron, J. (1999). Effects of reward on intrinsic motivation-Negative, neutral, and positive: Comment on Deci, Koestner, and Ryan (1999).

[13] Elliot, A. J. (2006). The hierarchical model of approachavoidance motivation. Motivation and emotion, 30(2), 111116, DOI 10.1007/s11031-006-9028-7.

[14] Elliot, A. J., \& Church, M. A. (1997). A hierarchical model of approach and avoidance achievement motivation. Journal of Personality and Social Psychology, 72, 218-232. [15] Förster, J., Grant, H., Idson, L. C., \& Higgins, E. T. (2001). Success/failure feedback, expectancies, and approach/avoidance motivation: How regulatory focus moderates classic relations. Journal of Experimental Social Psychology,37(3), 253-260.

[16] Freud, S. (1915). Repression. In the standard edition of Complete Psychological Works of Sigmund Freud, vol. XIV. London: Hogarth, 1957.

[17] Hamari, J., \& Koivisto, J. (2015). Why do people use gamification services? International Journal of Information Management, 35(4), 419-431.

[18] Herger, M. (2014). Enterprise Gamification: Engaging people by letting them have fun. CreateSpace Independent Publishing Platform; 1 edition.

[19] Hickey, M. (2010). Nissan's Leaf featuring automatic gaming system. Retrieved September 7, 2012.

[20] Higgins, E. T. (1997). Beyond pleasure and pain. American Psychologist, 52, 1280-1300.

[21] Huotari K., Hamari J. (2016). A Definition for Gamification: Anchoring Gamification in the Service Marketing Literature, Electron Markets, DOI $10.1007 / \mathrm{s} 12525-015-0212-\mathrm{z}$ 
[22] Huotari, K., \& Hamari, J. (2012, October). Defining gamification: a service marketing perspective. In Proceeding of the 16th International Academic MindTrek Conference (pp. 17-22). ACM.

[23] James, W. (1890). The principles of psychology (vol. 2). NY: Henry Holt \& Co.

[24] Kasser, T. (2002). Sketches for a self-determination theory of values. Handbook of self-determination research, 123-140.

[25] Kluger, A. N., \& DeNisi, A. (1996). The effects of feedback interventions on performance: a historical review, a meta-analysis, and a preliminary feedback intervention theory. Psychological bulletin, 119(2), 254.

[26] Lee, C.K. (1999): A Simulation Study on the Energy Saving Strategy of Train Operation. Proceedings of the World Congress of Railway Research WCRR 99, Tokyo, 1999.

[27] Luke, T., Brook-Carter, N., Parkes, A. M., Grimes, E., \& Mills, A. (2006). An investigation of train driver visual strategies. Cognition, Technology \& Work,8(1), 15-29.

[28] Marczewski, A. (2015). Even Ninja Monkeys Like to Play: Gamification, Game Thinking \& Motivational Design. Blurb.

[29] National Transportation Safety Board (2008). "Railroad Accident Report: Collision of Metrolink Train 111 with Union Pacific Train LOF65-12 Chatsworth, California, September 12, 2008”.

[30] Ng, J. Y., Ntoumanis, N., Thøgersen-Ntoumani, C., Deci, E. L., Ryan, R. M., Duda, J. L., \& Williams, G. C. (2012). Self-determination theory applied to health contexts a meta-analysis. Perspectives on Psychological Science, 7(4), 325-340.

[31] Nissan Eco-Drive, http://www.nissanglobal.com/EN/ENVIRONMENT/CAR/FUEL_COST/GA SOLINE/ [access: 15th of June 2016].

[32] Nukta, A., Haueis, M., Spitzer, M., \& Hille, K. (2011). Designing learning environments in assembly lines through self-determination. Procedia - Social and Behavioral Sciences, 29, 752-757. http://doi.org/10.1016/j.sbspro.2011.11.301.

[33] Ordinance of the Transport Minister of Poland. On the medical tests necessary to receive or prolong a train driver licence (15th of May 2011). Rozporządzenie Ministra Infrastruktury w sprawie badań koniecznych do otrzymania świadectwa maszynisty i zachowania jego ważności. Dziennik Ustaw nr 65.

[34] Pelletier, L.G. (2002). A Motivational Analysis of SelfDetermination Theory for Pro-Environmental Behaviors, [in:] Handbook of Self-Determination Theory, The University of Rochester Press, NY 2002.

[35] Pink, D. H. (2011). Drive: The surprising truth about what motivates us. Penguin.

[36] PKP SA Annual Report 2014, http://pkpsa.pl/grupapkp/raporty/Annual-Report-PKP-Group-2014_ENG.pdf, [access: 15/03/2016].

[37] Przewozy Regionalne (Regional Transport) Annual Report 2013, http://www.przewozyregionalne.pl/sites/default/files/pliki/1 31/raport-roczny-pr-2013-2.pdf, [access: 15/03/2016]. [38] Reeve, J. (2002). Self-determination theory applied to educational settings.
[39] Ryan, R., \& Deci, E. (2000). Intrinsic and Extrinsic Motivations: Classic Definitions and New Directions. Contemporary Educational Psychology, 25(1), 54-67. http://doi.org/10.1006/ceps.1999.1020.

[40] Ryan, R.M., Deci, E.L. (2002), An Overview of SelfDetermination Theory: An Organismic-Dialectical Perspective, [in:] Handbook of Self-Determination Theory, The University of Rochester Press, NY 2002.

[41] Stam, M. (2012). The Use of Gamification to Drive Behavioural Change - Lessons from the Strategic Platform for ITS (SPITS) and SCANIA, 19th ITS World Congress, Vienna, Austria, 22/26 October 2012.

[42] Thorndike, E. L. (1927). The law of effect. The American Journal of Psychology, 39(1/4), 212-222.

[43] Union Internationale des Chemins (2002), Energy Efficient Driving Strategies, http://www.railwayenergy.org/static/Energy_efficient_driving_strategies_74.p hp [access: 15th of June 2016].

[44] Vallerand, R.J., Ratalle, C.F., Intrinsic and Extrinsic Motivation: A Hierarchical Model, [in:] Handbook of SelfDetermination Theory, The University of Rochester Press, NY 2002.

[45] Werbach, K. (2014). (Re)Defining Gamification: A Process Approach, Persuasive Technology (pp. 266-272), Springer International Publishing.

[46] Werbach, K., \& Hunter, D. (2012). For the win: How game thinking can revolutionize your business. Wharton Digital Press.

[47] Williams, G. C. (2002). 11: Improving Patients' Health Through Supporting the Autonomy of Patients and Providers. Handbook of self-determination research, 233. [48] www.waze.com, [access: 31/08/2016]. 